OPEN ACCESS

Approved by:

Frontiers in Psychology,

Frontiers Media SA, Switzerland

*Correspondence:

Justine M. Gat

j.gatt@neura.edu.au

Specialty section

This article was submitted to Clinical and Health Psychology,

a section of the journal

Frontiers in Psychology

Received: 26 July 2018

Accepted: 16 August 2018

Published: 07 September 2018

Citation:

Bloch-Jorgensen ZT, Cilione PJ,

Yeung WWH and Gatt JM (2018)

Corrigendum: Centeredness Theory:

Understanding and Measuring Well-Being Across Core Life Domains.

Front. Psychol. 9:1648

doi: 10.3389/fpsyg.2018.01648

\section{Corrigendum: Centeredness Theory: Understanding and Measuring Well-Being Across Core Life Domains}

\author{
Zephyr T. Bloch-Jorgensen ${ }^{1,2}$, Patrick J. Cilione ${ }^{3}$, William W. H. Yeung ${ }^{4}$ and \\ Justine M. Gatt ${ }^{4,5 *}$ \\ ${ }^{1}$ MAP Corp. Pte. Ltd., Atlanta, Atlanta, GA, United States, ${ }^{2}$ MAP Corp. Pte. Ltd., Singapore, Singapore, ${ }^{3}$ Sciens Pty. Ltd., \\ Bundoora, VIC, Australia, ${ }^{4}$ School of Psychology, University of New South Wales, Sydney, NSW, Australia, ${ }^{5}$ Neuroscience \\ Research Australia, Randwick, NSW, Australia
}

Keywords: wellbeing, flourishing, mental health, mindfulness, self-actualization, goal-setting, COMPAS-W

\section{A Corrigendum on}

Centeredness Theory: Understanding and Measuring Well-Being Across Core Life Domains by Bloch-Jorgensen, Z. T., Cilione, P. J., Yeung, W. W. H., and Gatt, J. M. (2018). Front. Psychol. 9:610. doi: 10.3389/fpsyg.2018.00610

In the original article, there was a mistake in Supplementary Figure 1 as published. The Supplementary Figure that was submitted at the time of publishing was mislabeled. The corrected Supplementary Figure 1 appears below. The authors apologize for this error and state that this does not change the scientific conclusions of the article in any way.

The original article has been updated.

Conflict of Interest Statement: ZB-J is CEO of MAP Corporation Pte., Ltd. and will receive income from MAP Corporation Pte., Ltd. MAP Corporation Pte., Ltd. developed and owns the MAP technology. MAP is offered as not-for-profit product for individuals and for-profit for enterprises with financial interest for ZB-J as stockholder. PC is Director of Sciens Pty. Ltd., with $50 \%$ ownership in the company. JG is a stockholder in MAP Corporation Pte., Ltd. No authors received payment from MAP Corporation Pte., Ltd. for this work. WY declares that the research was conducted in the absence of any commercial or financial relationships that could be construed as a potential conflict of interest.

Copyright () 2018 Bloch-Jorgensen, Cilione, Yeung and Gatt. This is an open-access article distributed under the terms of the Creative Commons Attribution License (CC BY). The use, distribution or reproduction in other forums is permitted, provided the original author(s) and the copyright owner(s) are credited and that the original publication in this journal is cited, in accordance with accepted academic practice. No use, distribution or reproduction is permitted which does not comply with these terms. 
Self is divided into four sub-domains. It measures each sub-domain and the interrelationship between the four sub-domains of Inspiration, Contentment, Adaptability and Awareness. A strong self score indicates a durable sense of self and personal identity. Self delineates the degree to which the individual aspires for a future that they find meaningful and enriching via a set of clear and intrinsically rewarding goals. A strong score measured over time - indicates the degree of likeliness that these aspirations and goals will be achieved.
Community is divided into four subdomains. It measures each sub-domain and the interrelationship between the four sub-domains of Confidence, Sympathy,

Empathy and Sensitivity. The

Community score relates to a group

of people living in the same place or unified by a common interest. It includes one's local community, wider community, and includes the world as a body of nation states unified by common interests like climate related challenges, energy and migration; amplified by an unprecedented accessibility to information through the internet, media and International travel.
Relationship is divided into four sub-domains

It measures each sub-domain and the interrelationship between the four sub-domains of Attentiveness. Enrichment, Connection, and Understanding. Relationship identifies the degree to which an individual is able to relate intimately and to maintain a deep and rich connection. A high relationship score suggests that the individual finds a high degree of meaning and satisfaction in the relationship.

Family is divided into four sub-domains. It measures each sub-domain and the interrelationship between the four subdomains of Care, Participation, Communication and Receptiveness. A strong Family score indicates a cohesive sense of family and familial belonging. Family measures the individual's ability to address difficult situations, which have deep inward significance. Family also identifies the individual's ability to foster meaningful bonds. A high scores connotes tenacity, self-control, and the ability to be responsive in emotionally challenging situations and the ability to maximise opportunities to create Family mutually meaningful bonds.

Supplementary Figure 1 | Domain Descriptions.

Work is divided into four sub-domains. It measures each sub-domain and the interrelationship between the four sub-domains of Innovation, Supportiveness, Engagement and Accountability. A high work score indicates that the individual is an active and productive contributor in the workplace. Work indicates the degree to which the individual finds their work meaningful and to what degree work is embedded with purposive activity. 